\title{
Performance of hymenopteran insects as pollinators of pumpkin in Meghalaya
}

\author{
Rachna Pande $^{1^{*}}$ and V. K. Verma ${ }^{2}$ \\ ${ }^{1}$ Division of Crop Protection, ICAR Research Complex for NEH Region, Umroi Road, Umiam - 793103 \\ (Meghalaya), INDIA \\ ${ }^{2}$ Division of Horticulture, ICAR Research Complex for NEH Region, Umroi Road, Umiam - 793103 (Meghalaya), \\ INDIA \\ "Corresponding author. E-mail: rachna.ento@gmail.com
}

Received: January 16, 2016; Revised received: June 3, 2016; Accepted: October 10, 2016

\begin{abstract}
Pumpkin is a major cultivated crop particularly in north eastern states of India that depends on insects for the pollination, as the pollens of these plants are large sized and sticky. In the present study, field and lab experiments were conducted to determine the efficiency of the pollinators of pumpkin based on their diversity, relative abundance and foraging activity. Total four hymenopteran insect pollinators were observed in field viz., bumble bee, little honey bee, Indian honey bee and Digger bee. On the basis of abundance and relative abundance bumble bee was identified as most abundant pollinator of pumpkin with 69.69 per cent mean relative abundance as other pollinators mean relative abundance was less than 25 per cent and it was only 3.49 per cent for Indian honey bee. Foraging speed and foraging rate of bumble bee was $7.13 \mathrm{sec} / \mathrm{flower}$ and foraging rate was $3.80 \mathrm{flower} / \mathrm{minute}$. To ensure the efficient pollinator of pumpkin flower, pollen carrying capacity, pollen deposition and percent deposition of viable pollen was studied for all the pollinators in field and laboratory condition. The pollen carrying capacity of pollinators ranged from more than $7 \mathrm{mg}$ to $1 \mathrm{mg}$. It was highest for bumble bee which was $7.33 \mathrm{mg}$ followed by little honey bee $(6.66 \mathrm{mg})$ and least pollen carrying capacity was observed in Digger bee $(1.67 \mathrm{mg})$. Pollen depositions by pollinators on stigma in a single visit was again highest for bumble bee (565 pollen grains) with maximum number of viable pollen deposition 224.33 pollen grains out of which 39.7 per cent pollen was viable. So on the basis of above result it can be concluded that bumble bee was the most abundant and most efficient pollinator of pumpkin.
\end{abstract}

Keywords: Bumble bee, Indian honey bee, Pollen carrying capacity, Relative abundance, Viable pollen

\section{INTRODUCTION}

Vegetable cultivation is important in the agricultural economy of India and particularly in north eastern states of India. Farmers of north eastern states are small, marginal and mostly depend on hill farming for their subsistence. Meghalaya in general is known for its good quality of vegetable in Northeastern region (Kumar and Badal, 2004). Pumpkins are a major crop that depends on insects for the pollination as the pollens of these plants are large in size and sticky. Since few years, numbers of pollinators have been reduced because of existing threat due to wax moth, mites, wasps and new threats as in case of honey bee, wax beetle (Pande et al., 2015). The absence of sufficient efficient pollinators can result in low fruit yield and reduced fruit size (Walters and Taylor, 2006). Different sized wild pollinator species increase pumpkin pollination. Pollinator exclusion by bagging female flowers caused plants to abort the fruit of pumpkin (Hoehn et al., 2008). Abiotic factors like unfavorable conditions (Wien, 1997) and human intervention in form of artificial pollination which abort the female flower, indiscriminate use of pesticides that kills the pollinators aid in reducing the yields (Garibaldi, 2014;
Anonymous, 2016). Therefore reducing the use of synthetic insecticides that are toxic provide an important benefit to pollinators (Tuell and Isaacs, 2010).

For enhanced production of pumpkin, understanding the diversity of insect visitors, their abundance, foraging behavior and comparative pollination biology is essential. These parameters will help the farmers to find out the appropriate time for application of pesticide as it is recommended that do not spray the crop when pollinators are abundant in crop vicinity. Comparative study of pollination biology of different pollinators will be helpful for the pollination study and breeders to use the most efficient pollinators as in managed pollination programmes of that crop.Therefore, keeping in view the above aspects the present study was conducted at ICAR Research Complex for NEH Region Umiam Meghalaya, India to assess the work performance of Hymenopteran insects as pollinators of pumpkin and determine the efficient pollinator.

\section{MATERIALS AND METHODS}

The experiment was carried out at farm of Division of Horticulture (ICAR Research Complex for NEH Region) Umiam and nearby area of ICAR. The initial 
study was undertaken at $15 \%$ flowering stage in the month of June-July and August during rainy season 2014. The study to find out the various insects fauna visiting the flowers were recorded at various time interval starting from $0500 \mathrm{~h}$ to $0800 \mathrm{~h}$ of the day, depending on anthesis period of pumpkin crop. Data on abundance, foraging activity (speed and rate) and pollination biology (pollen carrying capacity, pollen deposition on stigma and pollen viability) was replicated thrice.

Abundance and relative abundance of insect visitors: The observation on pumpkin crops was initiated at $15 \%$ flowering stage at 2 week intervals according to their anthesis period to monitor the visiting pollinator abundance at which time period which group of pollinator dominate the crop visitation. Then the data was averaged species wise to draw the conclusion about dominant group and peak foraging time (Pateel and sattagi, 2007). Relative abundance of pollinator was worked out by using formula after pooling all the data and expressed in percentage (Nath and Viraktamath, 2010). The abundance and relative abundance of each pollinator was calculated by watching the number of visits by each insect $/ \mathrm{m}^{2} / 5$ minutes.

Foraging activity (foraging rate and foraging speed): Time spent per flower and number of flowers visited per minutes were taken as the indicators of foraging speed and rate respectively (Free, 1993).

Pollen carrying capacity of insect pollinators: The bees collecting pollen were trapped randomly, anaesthetized with chloroform and weighed. Later the pollen loads were brushed off from their bodies by using brush and vortex shaker and weight of the bees were determined again (Kumar et al., 2012). Difference between initial weight of insect pollinator with pollen and later weight of insect pollinator without pollen was considered as a pollen carrying capacity or pollen load of a respective insect pollinator.

Pollen deposition and percentage of viable pollen grain transferred by insect pollinators: Pollen deposition represents the amount of pollen deposited on stigma by an insect. To assess the amount of pollen deposited on stigma, a flower was bagged before anthesis were opened one by one for the insect to visit following the method of Reddi and Reddi, 1983. When such flowers received first visit, their stigmas were plucked and examined for number of pollen deposited following the pollen count by using Phase Contrast Microscope. Viability of pollen grains was tested using the pollen germination medium, Brewbaker and Kwack's culture medium (Brewbaker and Kwack, 1963). Viability was measured based on the number of pollen grains having pollen tube growth. Burst pollen grains and budded ones were not counted as germinated. Budding refers to pollen grains where pollen tubes do not grow longer than the diameter of pollen grain. Random counts of pollen grains were made in each replication under Phase contrast microscope.
Statistical analysis: In order to compute variance of different studies, the statistical constant i.e., mean, standard error of mean, critical difference (CD) for each quantitive characters were computed by the method of analysis of variance used generally for randomized block design (RBD) (Snedecor and Cochran, 1968). The results were computed at 5\% level of significance. To represent the results of relative abundance, pollen carrying capacity, pollen deposition and percentage of viable pollen average of data were calculated by simple calculation.

\section{RESULTS AND DISCUSSION}

Diversity of insect pollinators on pumpkin: The data on diversity of insect pollinators in pumpkin was recorded during year 2014 and listed in Table 1 revealed four hymenopteran insect pollinators. The pollinators represented three genera and four species belonging to the family apidae viz., Bumble bee, Bombus sp; Indian honey bee, Apis cerena Himalaya; little honey bee Apis florea; and Digger bee Anthophora sp. Similarly Kumar et al. (2012) reported total seven insects as visitors of pumpkin flower out of which four were hymenopteran. The diversity of insect pollinators was almost similar to present study other than the bumble bee.

Abundance of insect pollinator at different time period: All the visitors in general were recorded from the $0500 \mathrm{hrs}$ in pumpkin which gradually decline after $0800 \mathrm{hrs}$. The observation recorded on abundance of insect pollinators in pumpkin revealed that hymenopteran were the only abundant pollinators. Similar results were reported by Pande et al. (2016) that hymenopterans were the most abundant pollinators of chow chow in Meghalaya. Bumble bee was the most abundant pollinator of the target crop with maximum mean abundant population of $24.56 / \mathrm{m} 2 / 5 \mathrm{~min}$ during 0600 - $0700 \mathrm{hrs}$ followed by little honey bee with mean abundant population of $13.22 / \mathrm{m} 2 / 5 \mathrm{~min}$, during 0600 - 0700 hrs, Indian honey bee with mean abundant population of $1.72 / \mathrm{m} 2 / 5 \mathrm{~min}$, during $0600-0700 \mathrm{hrs}$ and Digger bee with mean abundant population of $1.06 / \mathrm{m} 2 / 5 \mathrm{~min}$ during $0700-0800 \mathrm{hrs}$. Abundance of bumble bee was ranged from $12.67 / \mathrm{m} 2 / 5 \mathrm{~min}$ to $27.00 / \mathrm{m} 2 / 5 \mathrm{~min}$ with maximum abundance during July I and III week at 0600 to $0700 \mathrm{hrs}$. Abundance of Little honey bee was ranged from $0.67 / \mathrm{m} 2 / 5 \mathrm{~min}$ to

Table 1. Diversity of pollinators in pumpkin flowers at Meghalaya.

\begin{tabular}{lllll}
\hline $\begin{array}{l}\text { S. } \\
\text { N. }\end{array}$ & Order & Family & $\begin{array}{l}\text { Common } \\
\text { name }\end{array}$ & Insect Spp \\
\hline 1 & Hymen- & Apidae & Bumble bee & Bombussp \\
& optera & & Indian honey & Apiscerenahi- \\
& & & bee & malaya \\
& & & Little honey & Apisflorea \\
& & & \\
& & & bee & \\
& & & Digger bee & Anthophora sp.
\end{tabular}


Table 2. Abundance of insect pollinators on pumpkin during 2014.

\begin{tabular}{lllllllllllll}
\hline \multicolumn{1}{r}{ Time (hrs) } & \multicolumn{1}{l}{ Bumble bee } & \multicolumn{4}{c}{ Little honey bee } & \multicolumn{3}{ll}{ Indian honey Bee } & \multicolumn{3}{l}{ Digger bee } \\
\cline { 2 - 12 } Weeks & $0500-$ & $0600-0700$ & $0700-$ & $0500-$ & $0600-$ & $0700-$ & $0500-0600-$ & $0700-$ & $0500-0600-$ & $0700-$ \\
\hline June I & 0600 & & 0800 & 0600 & 0700 & 0800 & 0600 & 0700 & 0800 & 0600 & 0700 & 0800 \\
June III & 23.33 & 24.67 & 19.67 & 6.67 & 14.33 & 10.00 & 2.00 & 2.67 & 2.33 & 0.00 & 0.67 & 1.00 \\
July I & 23.33 & 26.33 & 16.67 & 3.00 & 14.00 & 8.00 & 1.00 & 2.67 & 1.00 & 0.33 & 1.67 & 1.33 \\
July III & 20.33 & 27.00 & 16.67 & 1.67 & 14.33 & 6.67 & 0.67 & 1.67 & 1.00 & 0.00 & 1.00 & 1.33 \\
August I & 19.33 & 27.00 & 14.33 & 1.33 & 15.00 & 5.67 & 0.67 & 2.00 & 0.67 & 0.00 & 1.00 & 1.00 \\
August III & 19.33 & 22.67 & 13.33 & 0.67 & 10.67 & 5.00 & 0.33 & 0.67 & 0.00 & 0.00 & 1.00 & 1.00 \\
Mean & 20.33 & 19.67 & 12.67 & 1.00 & 11.00 & 3.00 & 0.00 & 0.67 & 0.00 & 0.00 & 0.33 & 0.67 \\
CD (P=0.05) & 21.00 & 24.56 & 15.56 & 2.39 & 13.22 & 6.39 & 0.78 & 1.72 & 0.83 & 0.06 & 0.94 & 1.06 \\
SEm \pm & 5.11 & 3.95 & 3.07 & 2.46 & 1.93 & 1.43 & 1.31 & 1.13 & 1.52 & 0.43 & 1.36 & 2.27 \\
\hline
\end{tabular}

Table 3. Percent relative abundance of pollinators on pumpkin.

\begin{tabular}{llllllll}
\hline \multicolumn{1}{c}{ Week } & June I & June III & July I & July III & August I & August III & $\begin{array}{l}\text { Mean } \\
\text { abundance }\end{array}$ \\
\cline { 1 - 3 } & & & & & & & relative \\
\cline { 1 - 3 } & 63.04 & 66.78 & 69.31 & 68.94 & 74.11 & 75.96 & 69.69 \\
Little honey bee & 28.88 & 25.17 & 24.55 & 25.00 & 21.88 & 21.63 & 24.51 \\
Indian Honey bee & 6.52 & 4.70 & 3.61 & 3.79 & 1.34 & 0.96 & 3.49 \\
Digger Bee & 1.55 & 3.36 & 2.53 & 2.27 & 2.68 & 1.44 & 13.83 \\
\hline
\end{tabular}

Table 4. Foraging behaviour of insect pollinators on pumpkin.

\begin{tabular}{llllccccc}
\hline \multirow{2}{*}{ Weeks } & Bumble bee & \multicolumn{3}{c}{ Little honey bee } & \multicolumn{2}{c}{ Indian honey bee } & \multicolumn{2}{c}{ Digger bee } \\
\cline { 2 - 9 } & $\begin{array}{c}\text { Rate } \\
\text { (No. of } \\
\text { flowers) }\end{array}$ & $\begin{array}{c}\text { Speed } \\
\text { (in sec- } \\
\text { onds) }\end{array}$ & $\begin{array}{c}\text { Rate } \\
\text { (No. of flow- } \\
\text { ers) }\end{array}$ & $\begin{array}{c}\text { Speed } \\
\text { (in seconds) }\end{array}$ & $\begin{array}{c}\text { Rate } \\
\text { (No. of flow- } \\
\text { ers) }\end{array}$ & $\begin{array}{c}\text { Speed } \\
\text { (in sec- } \\
\text { onds) }\end{array}$ & $\begin{array}{c}\text { Rate } \\
\text { (No. of flow- } \\
\text { ers) }\end{array}$ & $\begin{array}{c}\text { Speed } \\
\text { (in sec- } \\
\text { onds) }\end{array}$ \\
\hline June III & 3.67 & 6.33 & 6.00 & 5.67 & 9.00 & 3.33 & 6.00 & 2.67 \\
July I & 3.33 & 6.67 & 6.00 & 5.67 & 9.00 & 5.00 & 4.67 & 2.33 \\
July III & 4.00 & 7.33 & 6.67 & 5.33 & 9.33 & 4.67 & 3.00 & 2.33 \\
August I & 4.33 & 8.00 & 6.67 & 5.00 & 8.33 & 4.00 & 3.33 & 2.33 \\
August III & 3.67 & 7.33 & 7.00 & 4.00 & 7.33 & 4.67 & 2.33 & 2.67 \\
Mean & 3.80 & 7.13 & 6.47 & 5.13 & 8.60 & 4.33 & 3.87 & 2.47 \\
CD (P=0.05) & 1.96 & 1.35 & 2.56 & 3.00 & 1.68 & 1.50 & 1.37 & 1.97 \\
SEm \pm & 0.60 & 0.41 & 0.79 & 0.92 & 0.52 & 0.46 & 0.42 & 0.61 \\
\hline
\end{tabular}

Table 5. Pollen carrying capacity of different abundant insect visitors of pumpkin.

\begin{tabular}{llll}
\hline Insect pollinator & Body weight with pollen (mg) & Body weight without pollen (mg) & Pollen carrying capacity (mg) \\
\hline Bumble bee & 543.33 & 536 & 7.33 \\
Little honey bee & 356.66 & 349 & 6.66 \\
Indian Honey bee & 353.33 & 350 & 3.33 \\
Digger bee & 386 & 384.33 & 1.67 \\
\hline
\end{tabular}

Table 6. Pollen deposition and Percentage of viable pollen grains transferred by different abundant insect visitors of pump-

\begin{tabular}{llll}
\hline Insect pollinator & Number of pollen grain deposited/ visit & Number of viable pollen & Percentage of viable pollen \\
\hline Bumble bee & 565 & 224.33 & 39.70 \\
Little honey bee & 441.66 & 110.66 & 25.05 \\
Indian Honey bee & 345 & 32.33 & 9.37 \\
Digger bee & 311.66 & 7.33 & 2.35 \\
\hline
\end{tabular}

$15.00 / \mathrm{m} 2 / 5 \mathrm{~min}$ with maximum abundance during July III week at 0600 to $0700 \mathrm{hrs}$. Abundance of Indian Honey bee was ranged from $0.00 / \mathrm{m} 2 / 5 \mathrm{~min}$ to $2.67 / \mathrm{m} 2 / 5$ min with maximum abundance during June I and III week at 0600 to $0700 \mathrm{hrs}$. Abundance of Digger bee was ranged from $0.00 / \mathrm{m} 2 / 5 \mathrm{~min}$ to $1.67 / \mathrm{m} 2 / 5 \mathrm{~min}$ with maximum abundance during June III week at 0600 to 0700 hrs Table 2. Julier and
Roulston (2009) found out Honey bees (Apismellifera), specialist ground nesting bees (Peponapis pruinosa) and bumble bees (Bombus impatiens Cresson) were the most abundant bees visiting pumpkin blossoms. Likewise Bumble bee was the most abundant pollinator of ridge gourd with mean abundant population of $2.62 / \mathrm{m} 2 / 2 \mathrm{~min}$ during 1600-1700 hrs. (Anonymous, 2014). 
Relative abundance of insect pollinators on cucurbits: The present investigation was done to find the relative abundance of the insect pollinators i.e., bumble bee, little honey bee, Indian honey bee and Digger bee as shown in table 3. Relative abundance of Bumble bee was highest throughout the study with maximum relative abundance of $75.96 \%$ during third week of August followed by $74.11 \%$ on first week of August and lowest was $63.04 \%$ during first week of June. It was observed that Bumble bee being the dominant pollinator with $69.69 \%$ mean relative abundance on pumpkin followed by little honey bee with $24.51 \%$ and digger bee with $13.83 \%$ relative abundance. The least mean relative abundance was calculated for Indian honey bee which was $3.49 \%$. The result was in support of Goodell (2008) reported that supplying more honey bee hives is unlikely to improve pollination. On the basis of abundance and relative abundance bumble bee was identified as an most abundant pollinator of Pumpkin.

Foraging behavior (speed and rate) of insect pollinators: The observation on foraging behaviour (Table 4) of bumble bee, little honey bee, Indian honey bee and Digger bee were conducted during the study revealed that the bumble bee had foraging speed with $7.13 \mathrm{sec} /$ flower and foraging rate with 3.80 flower /minute. Anonymous, 2014 reported foraging rate of bumble bee was 10.33 flowers/ minute and foraging speed was 6.33 seconds/ flower in ridge gourd. The foraging speed of abundant pollinator of pumpkin, bumble bee was ranged from $6.33 \mathrm{sec} /$ flower during third week of June to 8.00 sec/flower during first week of August. Number of flower visited per minute was highest during first week of August with 4.33 flowers/min and lowest with 3.33 flowers/min during first week of July. In case of little honey bee the foraging speed was ranged from $4.00 \mathrm{sec} /$ flower during third week of August to $5.67 \mathrm{sec} /$ flower during third week of June and first week of July. Number of flower visited per minute was highest during third week of August with 7.00 flowers/min and lowest with 6.00 flowers/ min during third week of June and first week of July. Observation recorded on foraging behavior of Indian honey bee revealed that foraging speed was ranged from $3.33 \mathrm{sec} /$ flower during third week of June to 5.00 sec/flower during first week of July. Number of flower visited per minute was highest during third week of July with 9.33 flowers/min and lowest with 7.33 flowers/min during third week of August.

In case of Digger bee the foraging speed was ranged from $2.33 \mathrm{sec} /$ flower during first and third week of July and first week of August to $2.67 \mathrm{sec} /$ flower during third week of June and august. Number of flower visited per minute was highest during third week of June with 6.00 flowers/min and lowest with
2.33 flowers/min during third week of August.

Pollination biology of insect pollinators on pumpkin Pollen carrying capacity of different abundant insect visitors of pumpkin: Comparative study of pollinators' pollination biology on pumpkin revealed that comparatively, Bumble bee carried a greater amount of pollen load than other insect pollinators' viz., little honey bee, Indian honey bee and Digger bee. Amount of pollen load carried by bumble bee was high $(7.33 \mathrm{mg})$, followed by little bee $(6.66 \mathrm{mg})$ and Indian honey bee $(3.33 \mathrm{mg})$. Digger bee $(1.67 \mathrm{mg})$ carried the least pollen load Table 5 . It has been reported that pollen carrying capacity of bumble bee was 228.67 number of pollen grains in ridge gourd. Debarma 2015 and Pande et, al. 2016 verified that Indian honey bee carries maximmun number of pollen 1613.00 number of pollen grains and 1575.00 number of pollen grains respectively during chow chow pollination (Anonymous 2014).

Pollen deposition and percentage of viable pollen grain transferred by insect pollinators: The amount of pollen deposited per single visit by Bumble bee was high (565.00 pollen grains /stigma/ insect visit) followed by, Little honey bee (441.66 pollen grains /stigma/insect visit), Indian Honey bee (345.00 pollen grains /stigma/insect visit) and Digger bee (311.66 pollen grains /stigma/insect visit ). The bumble bee (Bombus impatiens) have also been documented as better pollinators than the managed honey bee species in terms of harvesting and depositing pollen per single visit (Artz and Nault, 2011). Bumble bee deposited total 218.67 number of pollen grains on stigma of ridge gourd (Anonymous 2014). However regarding the efficiency of viable pollen deposition, the Bumble bee, deposited more amount of viable pollen 224.33 number of pollen, (39.70\%) followed by little honey bee, 110.66 number of pollen, $(25.05 \%)$ and Indian Honey bee 32.33 number of pollen, $(9.37 \%)$. The Digger bee was found to be less efficient in viable pollen deposition7.33 number of pollen $(2.35 \%)$ in case of pumpkin Table 6 . Similarly in ridge gourd Bumble bee deposited more percentage of viable pollen 70.1 per cent in a single visit (Anonymous 2014).

\section{Conclusion}

All over the results from the present study indicate that amongst the insect pollinators, hymenopterans, as the only most abundant frequent visitors. Among them bumble bee showed highest abundance during 0500 hrs to $0800 \mathrm{hrs}$ in Meghalaya. So, farmers should shift the time of application of insecticides to mange other insect pests according to the findings. All the pollinators had role in carrying pollen and viable pollen deposition. Therefore the most economical option to increase pumpkin production appears to be employing 
management practices that promote and conserve the native bees of Meghalaya like crop refugee, lower tillage etc. Conserving and enhancing native bee species may boost pumpkin production in Meghalaya.

\section{REFERENCES}

Anonymous (2014). Annual report 2014-15, ICAR Research Complex for NEH Region, Umiam, Meghalaya793103, India, pp 202. Published by Director ICAR Research Complex for NEH Region, Umiam, Meghalaya- 793103, India.

Anonymous (2016). Beekeepers, farmers and public Interest Groups Sue EPA over Failed oversight of Neonicotinoid -coated seeds. Pollinator News, Jan. 9, 2016. Published by Pollinator Stewardship Council.

Artz, D.R. and Nault, B.A. (2011). Performance of Apismellifera, Bombus impatiens, and Peponapis pruinosa(Hymenoptera: Apidae) as pollinators of pumpkin. Journal of Economic Entomology, 104: 1153-1161

Brewbaker, J. L. and Kwack, B. H. (1963). The essential role of calcium ion in pollen Engineering in crop improvement. In: Pollen physiology and biotechnology.

Debbarma, R. (2015). Study on diversity of pollinators in cucurbits and pollination biology of honey bee in chow-chow (Sechiumedule) at mid-hills of Meghalaya. M. Sc. (Agri.) thesis, College of Post Graduate Studies, Central Agricultural University, Umiam, Meghalaya, India.

Free, J. B. (1993). Insect pollination of crops, 2nd ed London: academic press.

Garibaldi, L. A., Carvalheiro, L. G., Leonhardt, S. D., Aizen, M. A., Blaauw, B. R. Isaacs, R., Kuhlmann, M., Kleijn, D., Klein, A. M., Kremen, C., Morandin, L., Scheper, J. and Winfree, R. (2014). From research to action: enhancing crop yield through wild pollinators. Frontiers in Ecology and the Environment, 12(8): 439447

Goodell, K. (2008). Contributions of native, unmanaged bees to pollination of pumpkin and squash in Ohio and correlates to their densities -http://www3.uakron.edu/ biology/pollination/Posters/Goodell_\% 20pollinator\% 20workshop\%202008.pdf

Hoehn, P. Tscharntke, T. Tylianakis, J.M. and SteffanDewenter, I. (2008). Functional group diversity of bee pollinators increases crop yield. P Roy Soc B-Biol Sci., 275: 2283-91
Julier, H.E. and Roulston, T.H. (2009).Wild bee abundance and pollination service in cultivated pumpkins. Journal of Economic Entomology, 102: 563-0573

Kumar, P., and Badal, P.S. (2004). Growth and instability of horticultural crops in North-Eastern India. Agricultural Situation in India, 61(7):499-504

Kumar, P., Baskaran, S., Sundraravadivelan, C., Anburaj, J. and Kuberan, T. (2012). Insect visitors of pumpkin,Cucurbita maxima Duch., in relation to temperature and relative humidity. Journal of Agricultural Technology, 8(2): 501-513

Nath, S. and Viraktamath, S. (2010). Pollinator fauna of sunflower and their relative abundance. Karnataka ournal Agriculture Sciences, 23 (3): 517-518

Pande, R. Thakur, N.S.A., Ngachan, S.V. and Rajkhowa, D.J. (2015). First record of wax beetle, Platybolium alvearium Blair (Coleoptera: Tenebrionidae), in Eastern Himalaya: A new threat to Indian honey bee (Apisceranafabricius) colonies. Journal of Entomological Research, 39 (3): 269-273

Pande,R., Verma, V.K. and Thakur, N.S.A. (2016). Pollinators diversity and pollination biology of Indian honey bee (Apiscerana) in Chow-chow at mid-hills of Meghalaya. National Conference on Hill Agriculture In Perspective, Feb. 26-28, 2016, GPBUAT, Pantnagar.

Pateel, M.C. and Sattagi, H.N. (2007). Abundance of Different Insect Pollinators Visiting Cucumber (Cucumis sativa L.) in Rabi Season. Karnataka Journal of Agricultural Scinces, 20(4): 853-854

Reddi, E.U.B. and Reddi, C.S. (1983). Pollination ecology of Jatrophagossypifolia (Euphorbiaceae). Proceedings of Indian AcadademicScience.(Plant Science), 92: 215-231

Snedecor, G.N. and Cochran, W.G. (1968). Statistical methods, 6th ed., Oxford \& IBH Publishing Co. New Delhi.

Tuell, J.K. and Isaacs, R. (2010). Community and speciesspecific responses of wild bees to insect pest control programs applied to a pollinator-dependent crop. Journal of Economic Entomology, 103: 668-75

Walters, S.A. and Taylor, B.H. (2006). Effect of honey bee pollination on pumpkin fruit set and yield. Hortscience, 41:370-373

Wien, H. C. (1997). The cucurbits: cucumber, melon, squash and pumpkin, In: The physiology of vegetable crops (H.C. Wien, ed.). CAB International, Wallingford, p. 345-386 